\title{
Influence of body mass on predicted values of static hyperinflation in COPD
}

This article was published in the following Dove Press journal:

International Journal of COPD

\section{Peter Alter' \\ Klaus F Rabe ${ }^{2,3}$ \\ Holger Schulz ${ }^{4}$ \\ Claus F Vogelmeier' \\ Rudolf A Jörres ${ }^{5}$}

'Department of Medicine, Pulmonary and Critical Care Medicine, Philipps

University of Marburg, Member of the German Center for Lung Research (DZL), Marburg, Germany; ${ }^{2}$ LungenClinic Grosshansdorf,

Member of the German Center for Lung Research (DZL), Airway Research Center North (ARCN), Grosshansdorf, Germany; ${ }^{3}$ ChristianAlbrechts University, Airway Research Center North (ARCN), Kiel, Germany; ${ }^{4} \mathrm{Helmholtz-Zentrum}$ München, Institute of Epidemiology, German Research Center for Environmental Health, Comprehensive Pneumology Center Munich (CPC-M), Member of the German Center for Lung Research (DZL), Munich, Germany; ${ }^{5}$ Institute and Outpatient Clinic for Occupational, Social and Environmental Medicine, University Hospital, LMU Munich, Comprehensive Pneumology Center Munich (CPC-M), Member of the German Center for Lung Research (DZL), Munich, Germany
Correspondence: Peter Alter Department of Medicine, Pulmonary and Critical Care Medicine, Philipps University of Marburg, Member of the German Center for Lung Research (DZL), Baldingerstrasse, Marburg 35033 , Germany

Tel +4964215866140

Fax +496421586 6149

Email alter@uni-marburg.de
Introduction: For interpretation of body plethysmographic static hyperinflation, reference values are of crucial importance. Earliest reference values have been published by the European Coal and Steel Community (ECSC) and are based on sex, body height and age as predictors. As obesity can lead to a reduction of functional residual capacity (FRC) in lung-healthy subjects, more recent approaches included body weight or body surface area. This raises the question whether these models are appropriate in patients with COPD-induced hyperinflation.

Method: Several FRC prediction models and their relation to body weight were analyzed in 1513 patients with stable COPD (mean [SD] age: 64.5 [8.2] years; GOLD grades 1-4: 219/722/484/88), a subset of the multicenter COPD and Systemic Consequences - Comorbidities Network cohort. Results: Absolute values of FRC were inversely related to body mass index $(p<0.001)$. Applying the ECSC equations to calculate predicted values, this pattern was maintained $(p<0.001)$. By contrast, an inverted, ie, positive, relation occurred when using equations that include body weight or surface area $(p<0.001)$. The present analysis confirmed the inverse relation of body mass and FRC in COPD, resulting from a restrictive ventilatory pattern by diaphragm elevation and decreased chest wall compliance in obesity. The weight influence in the prediction models, as obtained from lung-healthy controls, appears to lead to an overcorrection and consequently to an inappropriate overestimation of hyperinflation as indicated by FRC \%predicted in COPD.

Conclusion: It is concluded that models not including body weight as predictor, like the classical ECSC equations, could be superior in the interpretation of FRC in COPD.

Keywords: static hyperinflation, body plethysmography, functional residual capacity, COPD, body mass

\section{Introduction}

Reference values are crucial for the interpretation of lung function impairments in patients with airway disorders including COPD. While body plethysmography is not widely used in academic research, it appears to be established in clinical practice in various countries, ${ }^{1}$ as judged from the numbers of equipment sold. The first reference values to be used for body plethysmographic measures were published by the European Coal and Steel Community (ECSC) and are based on sex, height and age as predictors. ${ }^{2}$ More recent approaches include body weight or body surface area ${ }^{3-5}$ as obesity can lead to a reduction of functional residual capacity (FRC) in lunghealthy subjects. This raises the question whether these weight-including models are appropriate in patients in whom COPD induces lung hyperinflation, ${ }^{6}$ which may counteract effects of obesity on FRC. This would crucially affect the clinical interpretation of FRC measurements.

We therefore analyzed various FRC prediction models and their relation to body weight in patients with stable COPD using data from the German COPD cohort 
COSYCONET ( $\underline{\text { COPD }}$ and Systemic $\underline{\text { Consequences - }}$ Comorbidities Network).

\section{Methods}

In COSYCONET, 2,741 patients with stable COPD were enrolled. ${ }^{7}$ The study was approved by the Ethics Committee of the University of Marburg as coordinating center and by the ethics committees of all study centers; it is registered on ClinicalTrials.gov (registration number NCT01245933). All study participants provided written informed consent. For the present analysis, data from Visit 1 (recruitment), Visit 2 (6-month follow-up) and Visit 3 (18-month follow-up) were used. Spirometry and body plethysmography was performed after inhalation of $400 \mu \mathrm{g}$ salbutamol and $80 \mu \mathrm{g}$ ipratropium bromide ${ }^{7}$ following the recommendations by the American Thoracic Society (ATS)/European Respiratory Society $(\text { ERS })^{8}$ and Deutsche Gesellschaft für Pneumologie und Beatmungsmedizin (DGP). ${ }^{1,9}$ In 28 out of 31 study centers, the same equipment and software were used. All measurements were performed by experienced personnel following detailed written SOPs, and the data collected were subjected to careful quality control.

In patients with a ratio of forced expiratory volume in 1 second $\left(\mathrm{FEV}_{1}\right)$ to forced vital capacity $<0.70$, airway obstruction was quantified via $\mathrm{FEV}_{1}$ \% predicted $^{10}$ according to the GOLD criteria. ${ }^{11}$ Only patients with spirometric GOLD grades $1-4$ at Visit 1 were included into the present analysis. Static lung hyperinflation was measured as body plethysmographic FRC (intrathoracic gas volume). ${ }^{1}$

Five different reference equations were used to calculate \%predicted values of FRC: ECSC as referenced by Quanjer et al, ${ }^{2}$ Cordero et al, ${ }^{3}$ Koch et al ${ }^{4}$ and Garcia-Rio et al. ${ }^{5}$ Except for ECSC, all equations include body weight or surface area (calculated according to DuBois) as predictor but Garcia-Rio et $\mathrm{al}^{5}$ provided an additional equation without weight-related predictors (Table 1). Only patients with body mass index (BMI) $<40 \mathrm{~kg} / \mathrm{m}^{2}$ and plausible data on predicted FRC for all methods ( $<300 \%$ predicted) at all visits were included. For terms of a sensitivity analysis, patients with BMI $\geq 40$ $\mathrm{kg} / \mathrm{m}^{2}$ were included. Linear regression analysis was applied using FRC measured or predicted value as dependent variable and BMI as independent variable.

\section{Results}

Data from 1,513 patients of GOLD grades 1-4 ( $\mathrm{n}=219$ / $722 / 484 / 88$ ) were analyzed. Details of the baseline characteristics at Visit 1 are shown in Table 2. The mean (SD) duration from Visit 1 to Visit 2 was 196 (33) days and from Visit 2 to
Table I Regression equations for calculation of FRC \%predicted

\begin{tabular}{|c|c|c|}
\hline Reference & Sex & Method \\
\hline \multirow[t]{2}{*}{$\mathrm{ECSC}^{2}$} & Men & $2.34 \mathrm{H}+0.009 \mathrm{~A}-1.09$ \\
\hline & Women & $2.24 \mathrm{H}+0.001 \mathrm{~A}-\mathrm{I}$ \\
\hline \multirow[t]{2}{*}{ Cordero et $\mathrm{al}^{3}$} & Men & $0.089 H-0.033 W+0.018 A-10.185$ \\
\hline & Women & $0.052 \mathrm{H}-0.018 \mathrm{~W}+0.004 \mathrm{~A}-4.858$ \\
\hline \multirow[t]{2}{*}{ Koch et $\mathrm{al}^{4}$} & Men & $-10.419+0.0172 \mathrm{~A}+0.092 \mathrm{H}-0.0329 \mathrm{~W}$ \\
\hline & Women & $\begin{array}{l}-6.7285+0.0631 \mathrm{~A}-0.000519 \mathrm{~A}^{2}+ \\
0.0603 \mathrm{H}-0.0239 \mathrm{~W}\end{array}$ \\
\hline \multirow[t]{2}{*}{ Garcia-Rio et al ${ }^{5}$} & Men & $\begin{array}{l}-1.425+0.02188 \mathrm{~A}+0.0000007418 \mathrm{H}^{3}- \\
0.00000103 \mathrm{~W}^{3}\end{array}$ \\
\hline & Women & $2.276+0.0000008882 \mathrm{H}^{3}-1.96 \mathrm{BSA}$ \\
\hline Garcia-Rio et al ${ }^{5}$ & Men & $-1.215+0.02434 \mathrm{~A}+0.0000005659 \mathrm{H}^{3}$ \\
\hline $\begin{array}{l}\text { without weight- } \\
\text { related factors }\end{array}$ & Women & $0.563+0.0000004998 \mathrm{H}^{3}$ \\
\hline
\end{tabular}

Abbreviations: A, age (yr); BSA, body surface area $\left(\mathrm{m}^{2}\right)$; ECSC, European Coal and Steel Community; FRC, functional residual capacity; $\mathrm{H}$, standing height ( $\mathrm{m}$ ); $\mathrm{W}$, weight $(\mathrm{kg})$.

Visit 3 was 377 (55) days. The mean decline of FEV 1 between the visits ( 1 vs 2 and 2 vs 3 ) was $0.022 \mathrm{~L}$ (95\% confidence interval [CI] 0.010 to $0.033 \mathrm{~L}$ ) and $0.070 \mathrm{~L}(0.058$ to $0.082 \mathrm{~L})$, respectively. The mean change of FRC was $-0.007 \mathrm{~L}(-0.039$ to $0.025 \mathrm{~L})$ and $0.111 \mathrm{~L}(0.078$ to $0.144 \mathrm{~L})$, respectively. Despite the small changes during the follow-up, mean values of FRC and BMI from three visits were used in the correlation analyses to improve the signal-to-noise ratio. Correction for the trend did not lead to any qualitatively different results.

Absolute values of FRC were inversely related to BMI $(p<0.001$; Figure 1). Applying the ECSC equations, the pattern was maintained, ie, an increased BMI was related

Table 2 Baseline characteristics of the study cohort at Visit I $(\mathrm{n}=\mathrm{I}, 5 \mid 3)$

\begin{tabular}{ll}
\hline Parameter & $\begin{array}{l}\text { Mean values (SD) } \\
\text { or } \mathbf{n}(\%)\end{array}$ \\
\hline Anthropometry & \\
Age, years & $64.5(8.2)$ \\
Sex, m/f & $928 / 585$ \\
BMI, kg/m & $26.4(4.7)$ \\
Lung function and body plethysmography & \\
GOLD I/2/3/4 & $219 / 722 / 484 / 88$ \\
FEV, \%predicted & $54.97 \%(18.26 \%)$ \\
FRC, L & $4.79(1.17)$ \\
FRC \%predicted, ECSC & $147.0 \%(33.3 \%)$ \\
FRC \%predicted, Cordero et a ${ }^{3}$ & $143.5 \%(34.6 \%)$ \\
FRC \%predicted, Koch et al ${ }^{4}$ & $125.4 \%(28.8 \%)$ \\
FRC \%predicted, Garcia-Rio et al ${ }^{5}$ & $152.6 \%(34.3 \%)$ \\
FRC \%predicted, Garcia-Rio et al ${ }^{5}$ & $150.7 \%(35.0 \%)$ \\
without weight-related factors & \\
\hline
\end{tabular}

Note: The table shows mean values ( \pm standard deviations), except for sex and GOLD grade. FRC \%predicted following several methods.

Abbreviations: BMI, body mass index; ECSC, European Coal and Steel Community; FEV, \%predicted, forced expiratory volume in I second predicted according to GLI; FRC, functional residual capacity. 
A
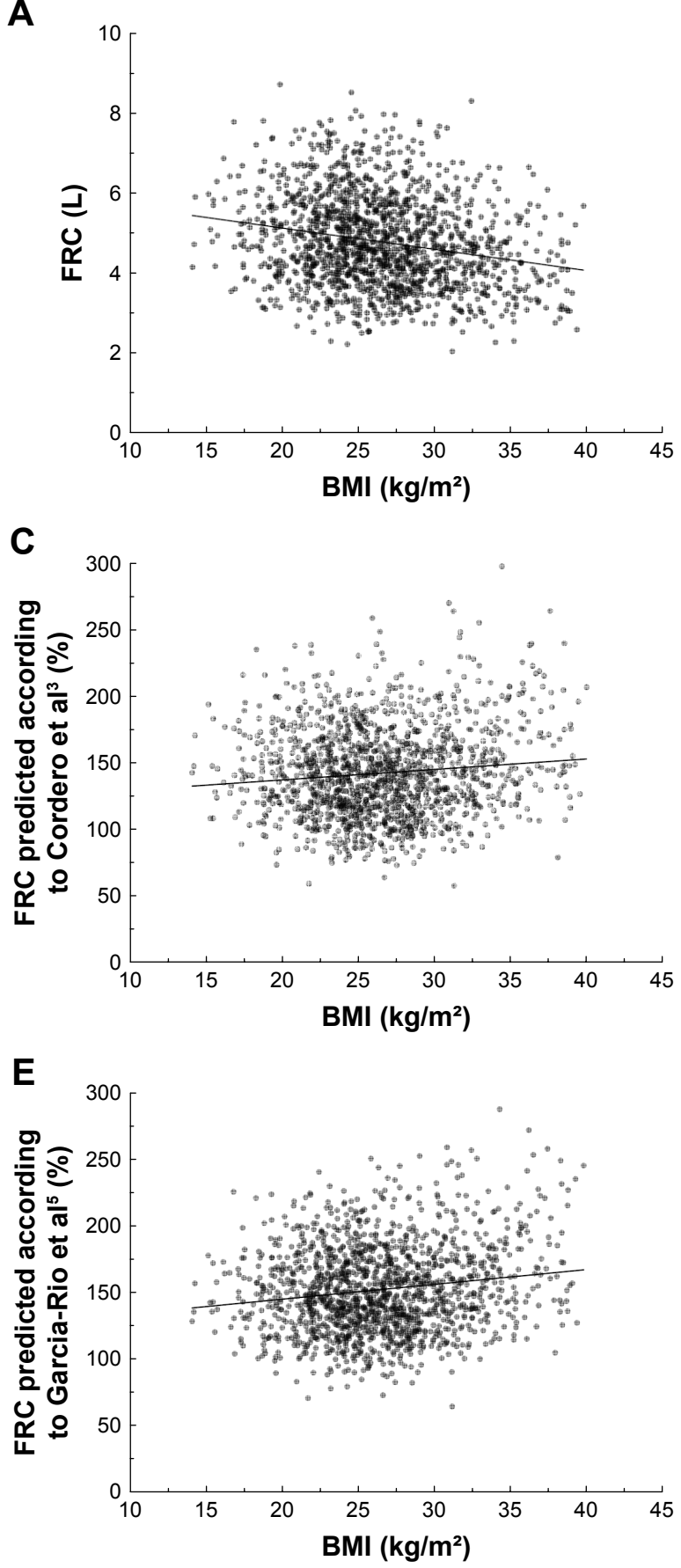

B

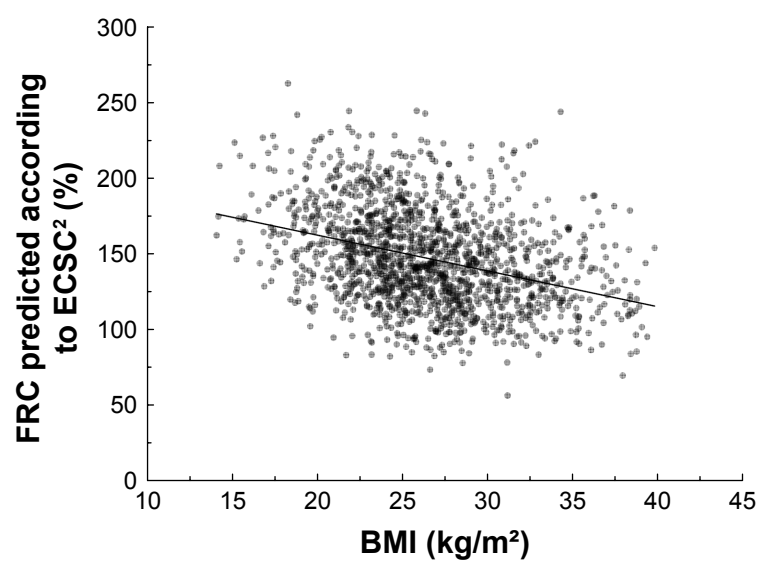

D
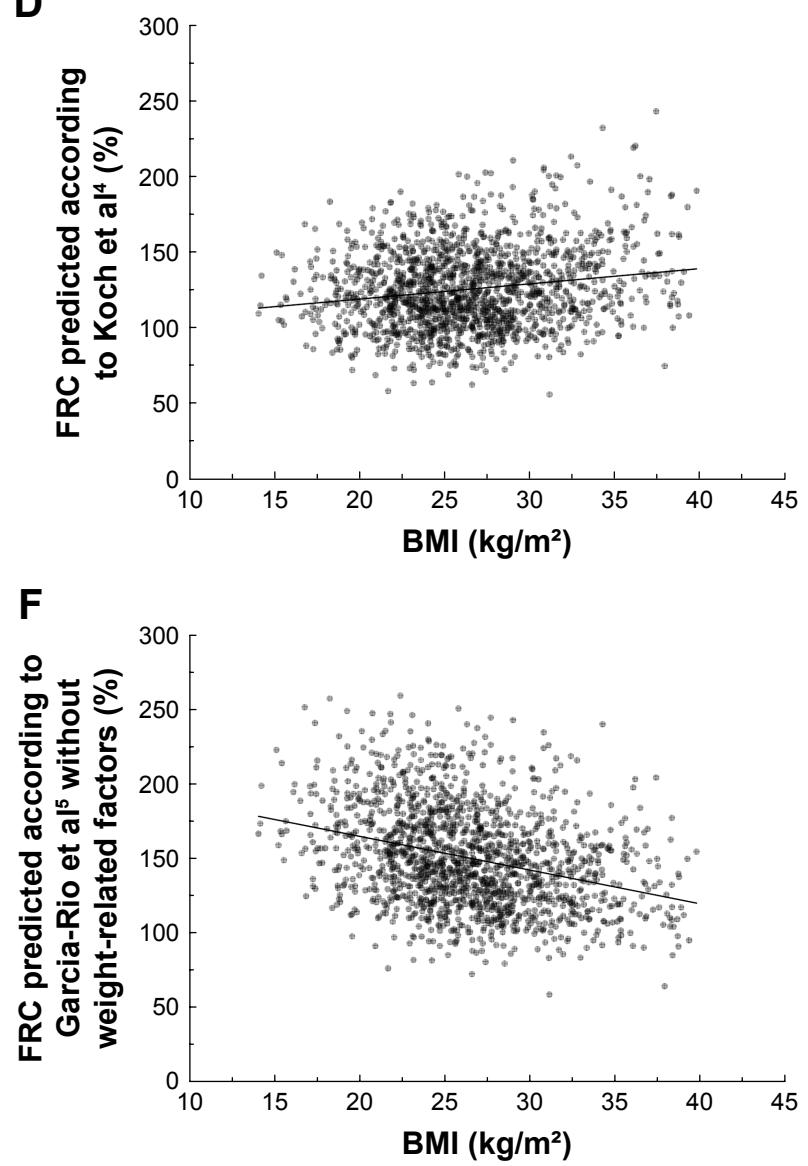

Figure I Scatter diagrams and regression lines $(p<0.00$ I each) of static lung volume (FRC) versus BMI in terms of absolute values $(\mathbf{A})$ and \%predicted by ECSC $(\mathbf{B})$ based on body height and age, as \%predicted by Cordero et $\mathrm{al}^{3}(\mathbf{C})$, Koch et $\mathrm{al}^{4}(\mathbf{D})$ and Garcia-Rio et al ${ }^{5}(\mathbf{E})$ including body weight as predictor; in addition, as \%predicted by Garcia-Rio et al ${ }^{5}$ without weight-related factors (F).

Abbreviations: BMI, body mass index; ECSC, European Coal and Steel Community; FRC, functional residual capacity.

to a decreased FRC \%predicted $(p<0.001)$. By contrast, FRC \%predicted increased with BMI when using equations from Cordero et al, ${ }^{3}$ Koch et $\mathrm{al}^{4}$ and Garcia-Rio et al, ${ }^{5}$ which include body weight or surface area. Using the equations from Garcia-Rio et $\mathrm{al}^{5}$ without weight-related terms, a similar pattern as for the ECSC equations was observed ( $p<0.001$ each). The slope of the corresponding regression equation $(-2.257$;
$95 \%$ CI: -2.598 to -1.915$)$ did not significantly differ from that of ECSC values (-2.356; -2.675 to -2.038), but these slopes were clearly different from those of the other approaches (Cordero et al: 0.779 ; 0.428-1.129; Koch et al: 1.001; $0.722-1.280$; Garcia-Rio et al: $1.113 ; 0.765-1.460$ ). When individuals with $B M I \geq 40 \mathrm{~kg} / \mathrm{m}^{2}$ were included for the purpose of a sensitivity analysis, the observed effects were pronounced. 


\section{Discussion}

The analysis confirmed that static lung volume in terms of body plethysmographic FRC is inversely related to BMI, in line with pathophysiologic evidence. An increased adipose mass is known to cause elevation of the diaphragm, in addition to effects exerted by decreased chest wall compliance and inducing a restrictive ventilatory pattern. ${ }^{12}$ This relationship also occurred in patients with stable COPD when using the absolute values of FRC.

In clinical practice, FRC is evaluated relative to reference values derived from healthy individuals. Various regression equations have been published, which include sex, age and height as determinants. The ECSC equations are limited to these predictors. ${ }^{2}$ They yielded an inverse relationship between FRC \%predicted and BMI, just as the absolute values of FRC, thereby matching expectations from pathophysiology. The other equations included body weight or body surface area as predictors ${ }^{3-5}$ and resulted in an increase of FRC \%predicted with increasing BMI, which appears implausible. The most likely explanation is that in obese patients with COPD the negative weight term in the equations, as derived from lung-healthy subjects, leads to an overcorrection for weight in the predicted values and consequently to an overestimation of hyperinflation in terms of \%predicted. Conversely, if correct, it would suggest that lung volume in COPD patients with hyperinflation is, on average, less affected by obesity than in lung-healthy subjects.

Recognizing the potential problems in obese, lunghealthy subjects, Garcia-Rio et al already proposed a model without weight or weight-related predictors. ${ }^{5}$ In our COPD population, it yielded the same picture as the ECSC equations, suggesting that our findings are not due to the possibility that the ECSC equations ${ }^{13}$ are outdated. Moreover, the qualitative pattern of correlations was maintained when the range of BMI was limited to values $<30 \mathrm{~kg} / \mathrm{m}^{2}$, and therefore, our observations were also not due to unwarranted extrapolation of the prediction equations.

The comparison of methods for calculation of normal values is limited by the fact that different approaches for the assessment of hyperinflation have been used. The COSYCONET study as well as Koch et $\mathrm{al}^{4}$ used body plethysmography, whereas Cordero et $\mathrm{al}^{3}$ used multiplebreath helium washout. Although these differences limit comparability, they do not appear to bias the findings, as has been previously discussed. ${ }^{2,4,5}$ In healthy subjects, ie, those used for reference populations, FRC values derived by gas washout and body plethysmography are in parallel, whereas in COPD larger differences can occur. This, however, does not affect the application of the reference values in the quantification of deviations from normal, as underlined by the consistency of our findings.

\section{Conclusion}

Prediction equations for FRC that include body mass appear to favor an overestimation of the degree of hyperinflation in obese patients with COPD. Therefore, models without body weight, like the classical ECSC equations, could be superior in the evaluation of FRC in COPD. We believe that research groups and clinicians who use body plethysmography as a diagnostic tool should be aware of this finding and that the combined effects of COPD-related hyperinflation and BMI on lung volume measurements should be studied more thoroughly.

\section{Acknowledgments}

This work was supported by the German Federal Ministry of Education and Research (BMBF) Competence Network Asthma and COPD (ASCONET) and performed in collaboration with the German Center for Lung Research (DZL). The project was funded by the BMBF with grant number 01 GI 0881 and was supported by unrestricted grants from AstraZeneca GmbH, Bayer Schering Pharma AG, Boehringer Ingelheim Pharma GmbH \& Co. KG, Chiesi GmbH, GlaxoSmithKline, Grifols Deutschland GmbH, MSD Sharp \& Dohme GmbH, Mundipharma GmbH, Novartis Deutschland GmbH, Pfizer Pharma GmbH, Takeda Pharma Vertrieb $\mathrm{GmbH} \& \mathrm{Co}$. KG and TEVA GmbH for patient investigations and laboratory measurements. The funding bodies had no involvement in the design of the study, or the collection, analysis or interpretation of the data.

\section{Disclosure}

The authors report no conflicts of interest in this work.

\section{References}

1. Criée CP, Sorichter S, Smith HJ, et al. Body plethysmography - its principles and clinical use. Respir Med. 2011;105(7):959-971.

2. Quanjer PH, Tammeling GJ, Cotes JE, Pedersen OF, Peslin R, Yernault JC. Lung volumes and forced ventilatory flows. Eur Respir J. 1993;6(Suppl 16):5-40.

3. Cordero PJ, Morales P, Benlloch E, Miravet L, Cebrian J. Static lung volumes: reference values from a Latin population of Spanish descent. Respiration. 1999;66(3):242-250.

4. Koch B, Friedrich N, Völzke H, et al. Static lung volumes and airway resistance reference values in healthy adults. Respirology. 2013; 18(1):170-178.

5. Garcia-Rio F, Dorgham A, Pino JM, Villasante C, Garcia-Quero C, Alvarez-Sala R. Lung volume reference values for women and men 65 to 85 years of age. Am J Respir Crit Care Med. 2009;180(11):1083-1091.

6. Langer D, Ciavaglia CE, Neder JA, Webb KA, O’Donnell DE. Lung hyperinflation in chronic obstructive pulmonary disease: mechanisms, clinical implications and treatment. Expert Rev Respir Med. 2014;8(6): 731-749. 
7. Karch A, Vogelmeier C, Welte T, et al. The German COPD cohort COSYCONET: aims, methods and descriptive analysis of the study population at baseline. Respir Med. 2016;114:27-37.

8. Wanger J, Clausen JL, Coates A, et al. Standardisation of the measurement of lung volumes. Eur Respir J. 2005;26(3):511-522.

9. Vogelmeier C, Buhl R, Criée CP, et al. Leitlinie zur Diagnostik und Therapie von Patienten mit chronisch obstruktiver Bronchitis und Lungenemphysem (COPD) [Guidelines for the diagnosis and therapy of COPD issued by Deutsche Atemwegsliga and Deutsche Gesellschaft fur Pneumologie und Beatmungsmedizin]. Pneumologie. 2007;61(5):e1-e40. German.

10. Quanjer PH, Stanojevic S, Cole TJ, et al; ERS Global Lung Function Initiative. Multi-ethnic reference values for spirometry for the 3-95-yr age range: the global lung function 2012 equations. Eur Respir J. 2012; 40(6):1324-1343.
11. Vogelmeier CF, Criner GJ, Martinez FJ, et al. Global strategy for the diagnosis, management, and prevention of chronic obstructive lung disease 2017 report: GOLD executive summary. Eur Respir J. 2017; 49(3):pii:1700214.

12. Ladosky W, Botelho MA, Albuquerque JP Jr. Chest mechanics in morbidly obese non-hypoventilated patients. Respir Med. 2001;95(4): 281-286.

13. Standardized lung function testing. Report working party. Bull Eur Physiopathol Respir. 1983;19(Suppl 5):1-95.

International Journal of COPD

\section{Publish your work in this journal}

The International Journal of COPD is an international, peer-reviewed journal of therapeutics and pharmacology focusing on concise rapid reporting of clinical studies and reviews in COPD. Special focus is given to the pathophysiological processes underlying the disease, intervention programs, patient focused education, and self management protocols.

\section{Dovepress}

This journal is indexed on PubMed Central, MedLine and CAS. The manuscript management system is completely online and includes a very quick and fair peer-review system, which is all easy to use. Visit http://www.dovepress.com/testimonials.php to read real quotes from published authors.

Submit your manuscript here: http://www.dovepress.com/international-journal-of-chronic-obstructive-pulmonary-disease-journal 